\title{
Aplikasi Pemesanan Makanan Berbasis Mobile Pada Rumah Makan "Lek Nonong”
}

\author{
Adi Putra Nugraha ${ }^{1)}$, Kodrat Iman Satoto ${ }^{2)}$, Kurniawan Teguh Martono ${ }^{2)}$ \\ Program Studi Sistem Komputer Fakultas Teknik Universitas Diponegoro \\ Jalan Prof. Sudharto, Tembalang, Semarang, Indonesia \\ adiputranugraha25@yahoo.com
}

\begin{abstract}
The restaurant business that began growing in Semarang in particular areas Tembalang. Various types of food and drink offered by restaurants. Of course, to be able to compete the restaurant needs good management in the effort to obtain optimal benefits. Based on the problems need to develop an Order Food Mobile-Based Application to support the work processes of the restaurant, especially in the booking process and report transactions menu.

The mobile application was built using jQuery Mobile programming language and HTML. The use of mobile applications is supported by an application which is running on a desktop computer that was built using the programming language PHP, Javascript and MySQL databases. Modeling applications was built using DFD ( Data Flow Diagram ).

The results of the design Order Food Mobile-Based Application is an application that can be used for the work process and manage reports deals on restaurants, and also an application that can be used to enter the booking menu using mobile devices.
\end{abstract}

Key Terms: Mobile-Based Applications, jQuery Mobile, PHP, HTML, MySQL, Javascript, DFD (Data Flow Diagram).

\section{Pendahuluan}

$\mathrm{R}$ umah makan Lek Nonong yang berlokasi di daerah Tembalang kota Semarang menyediakan berbagai menu makanan dan minuman khas nusantara. Selama ini rumah makan tersebut masih menggunakan cara pengerjaan manual dalam pelayanannya, belum menggunakan aplikasi terkomputeriasi atau aplikasi berbasis mobile. Oleh sebab itu, perlu dikembangkan suatu aplikasi berbasis mobile yang dapat membantu proses pelayanan maupun proses rekap data untuk laporan transaksi yang dapat digunakan pada rumah makan Lek Nonong.

Aplikasi untuk rumah makan ini dapat menjadi salah satu solusi untuk memudahkan proses kerja dilingkungan rumah makan Lek Nonong, khususnya dalam proses pemesanan menu dan laporan transaksi. Dengan adanya suatu aplikasi yang dapat melakukan manajemen laporan dari transaksitransaksi terjadi pada rumah makan. Sehingga pengerjaan manual yang rentan akan kesalahan dan kurang efisien dapat dikurangi dengan aplikasi tersebut.

Bagaimana membuat sebuah aplikasi pemesanan makanan berbasis mobile yang dapat digunakan untuk memudahkan proses kerja dan memanajemen laporan transaksi pada rumah makan, serta aplikasi dapat memasukkan pemesanan menu menggunakan perangkat mobile? Pembahasan dalam makalah ini akan memaparkan mengenai perancangan dan hasil pengujian aplikasi yang dapat melakukan manajemen transaksi, pengelolaan data menu, maupun laporan transaksi pada rumah makan Lek Nonong.

\section{DASAR TEORI}

\section{A. Pemodelan Proses Data Flow Diagram (DFD)}

Menurut Andri (2004), DFD adalah suatu model logika data atau proses yang dibuat untuk menggambarkan dari mana asal data dan kemana tujuan data yang keluar dari sistem, dimana data disimpan, proses apa yang menghasilkan data tesebut dan interaksi antara data tersebut dan interaksi antara yang tersimpan dan proses yang dikenakan pada data tersebut.

DFD menggambarkan penyimpanan data dan proses yang mentransformasikan data. DFD menunjukan hubungan antara data pada sistem dan proses pada sistem.

\section{B. $P H P$}

PHP (Hypertext Preprocessor) merupakan bahasa pemrograman berbasis web yang memiliki kemampuan untuk memproses dan mengolah data secara dinamis. PHP dapat dikatakan sebagai sebuah server-side embedded script language, artinya semua sintaks dan perintah program yang ditulis sepenuhnya dijalankan oleh server, tetapi dapat disertakan pada halaman HTML biasa. Pada umumnya aplikasi yang dibangun menggunakna PHP akan memberikan hasil pada web browser, tetapi prosesnya secara keseluruhan dijalankan pada server. (Wahana Komputer, 2009)

Pada prinsipnya server akan bekerja apabila ada permintaan client. Dalam hal ini, client menggunakan kodekode PHP akan mengirim permintaan ke server.

\section{HTML}

Menurut Diar (2010), HTML (HyperText Markup Language) adalah suatu bahasa yang dikenali oleh web browser untuk menampilkan informasi dengan lebih menarik dibandingkan dengan tulisan teks biasa (plain text). Sedangakan web browser adalah program komputer yang digunakan untuk membaca HTML, kemudian menerjemahkan dan menampilkan hasilnya secara visual ke layar komputer.

Karena sebuah bahasa, maka HTML mempunyai aturan dan struktur tertentu untuk menuliskan perintah-perintahnya yang biasa dinamakan dengan Tag HTML. Aturan tersebut diawali dengan dengan lambang <tag $>$ dan biasanya akan diakhiri dengna lambang $</$ tag $>$

\section{JQuery Mobile}

JQuery Mobile adalah framework yang dioptimalkan untuk perangkat-perangkat layar sentuh (touch-optimized). Sebagai library, jQuery mobile yang juga dikenal sebagai library JavaScript maupun framework mobile ini 
dikembangkan oleh tim jQuery Project. Tujuan pengembangannya adalah berfokus pada pembuatan framework yang kompatibel dengan beraneka ragam perangkat smartphone dan tablet. (Wahana Komputer, 2013)

Kelebihan jQuery adalah kodenya ringan, menerapkan desain yang dapat beradaptasi dengan berbagai jenis perangkat mobile. JQuery Mobile memiliki sekumpulan plugin dan widget yang dimaksudkan untuk menyediakan API agar dapat dikenali di berbagai platform. Untuk implementasi kode, jQuery Mobile sangat mirip dengan jQuery UI.

\section{E. $M y S Q L$}

MySQL adalah salah satu perangkat lunak sistem manajemen basis data (database) SQL. Berbeda dengan basis data konvensional seperti .dat, .dbf, .mdb, MySQL memiliki kelebihan yaitu bersifat multithread, dan multi-user serta mendukung sistem jaringan. MySQL didistribusikan secara gratis dibawah lisensi GNU General Public License (GPL), namun ada juga versi komersial bagi kalangan tertentu yang menginginkannnya. (A.M Hirin \& Virgi, 2011)

\section{PERANCANGAN SISTEM}

\section{A. Analisis Kebutuhan}

Berikut ini merupakan analisis kebutuhan fugngsional dari sistem aplikasi pemesanan makanan berbasis mobile, yaitu:

1) Adanya pembagian pengguna menjadi lima kelompok pada aplikasi pemesanan makanan berbasis mobile sebagai berikut :
a. Pelayan (dengan login)
b. Kasir (dengan login)
c. Dapur (dengan login)
d. Operator (dengan login)
e. Admin (dengan login)

2) Adanya fasilitas pelayan untuk memasukkan pemesanan menu.

3) Adanya fasilitas palayan untuk mengubah pemesanan yang telah dimasukkan.

4) Adanya fasilitas dapur untuk menampilkan pemberitahuan dan daftar pemesanan menu.

5) Adanya fasilitas dapur untuk menampilkan pemberitahuan dan daftar pesan antar.

6) Adanya fasilitas dapur untuk memasukkan daftar belaja.

7) Adanya fasilitas kasir untuk mencetak nota transaksi pemesanan menu dan nota transaksi pesan antar.

8) Adanya fasilitas operator untuk memasukkan pemesanan antar.

9) Adanya fasilitas operator untuk mengubah pemesanan yang telah dimasukkan.

10) Adanya fasilitas admin untuk melihat laporan penjualan, laporan belanja, dan laporan pesan antar.

11) Adanya fasilitas admin untuk mengolah data pengguna aplikasi.

Berikutnya analisis kebutuhan non-fungsional dari sistem, yaitu :

1) Operasional
a. Dapat dijalankan menggunakan berbagai browser yang mendukung javascript untuk aplikasi pada perangkat komputer desktop.
b. Dapat dijalankan pada smartphone android.

2) Kemanan

a. Adanya penggunaan password dan pemilihan level dalam form login untuk membedakan user dan hak akses masing-masing.

\section{B. Analisis Sistem}

Tahap analisis sistem bertujuan menggambarkan segala sesuatu yang nantinya akan ditangani oleh perangkat lunak. Tahapan ini merupakan tahapan dimana permodelan merupakan representasi dari objek di dunia nyata. Perancangan aplikasi pemesanan makanan berbasis mobile ini menggunakan metode permodelan dekomposisi fungsional dan metode permodelan pemrograman terstruktur yaitu DFD (Data Flow Diagram). Berikut ini DFD level 0 yang menggambarkan dasar sistem pemesanan makan berbasis mobile yang akan didekomposisi lagi menjadi sistem yang lebih detail. Ada terdapat lima entitas dan satu proses yang dapat dilihat pada Gambar 1.

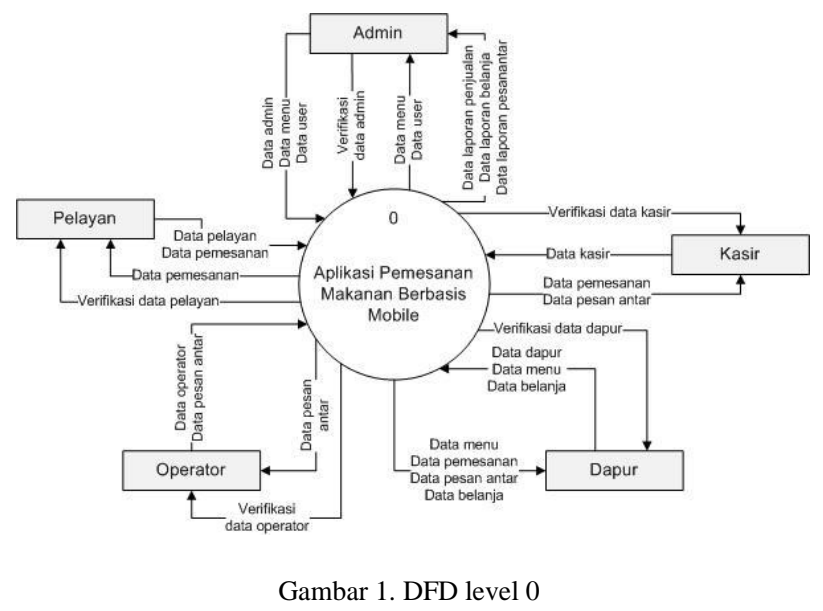

Berikut ini diagram dekomposisi fungsional secara keseluruhan aplikasi pemesanan makanan berbasis mobile yang ditunjukkan pada Gambar 2.

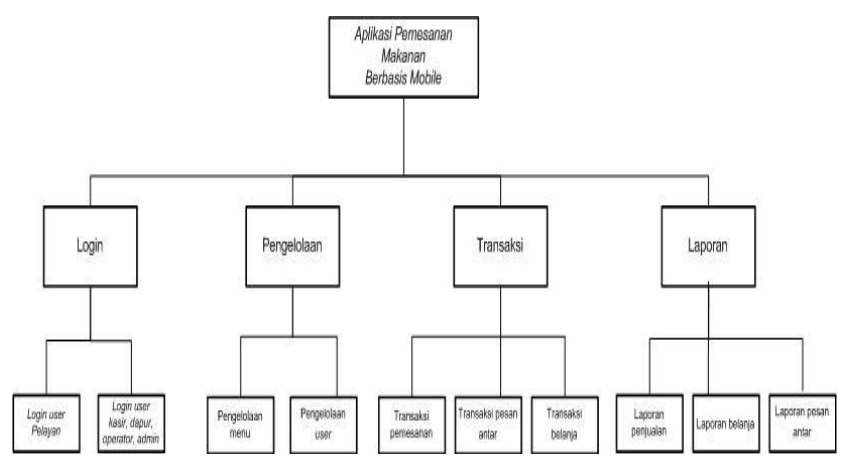

Gambar 2. Dekomposisi Fungsional

Berdasarkan DFD level 0 di atas, kemudian didekomposisi menjadi DFD level 1 seperti yang digambarkan pada gambar 3 berikut ini. 




Terdapat empat proses pada DFD level 1 sistem aplikasi pemesanan makanan berbasis mobile, yaitu :

\section{1) Login}

Merupakan proses validasi untuk dapat mengakses sistem aplikasi pemesanan makanan dan melakukan pemisahan user dalam mengaksesnya. Terdapat lima user dalam sistem tersebut dimana masing-masing memiliki otoritas tertentu dalam mengakses sistem.

2) Pengelolaan

Proses ini merupakan proses untuk melakukan pengelolaan terhadap data menu dan data user. Pada proses ini yang berhak melakukan pengelolaan adalah user admin.

\section{3) Transaksi}

Merupakan proses untuk melakukan transaksi, baik transaksi pemesanan, transaksi pesan antar, maupun transaksi belanja. Masing-masing transaksi tersebut dilakukan oleh user yang berbeda.

\section{4) Laporan}

Proses laporan ini merupakan proses untuk user admin dapat melihat laporan-laporan berdasarkan transaksi-transaksi yang dilakukan. Ada laporan penjualan, laporan pesan antar, dan laporan belanja.

DFD level 1 ini kemudian didekomposisi lagi menjadi proses yang lebih detil pada DFD level 2.

\section{Perancangan Basis Data}

Perancangan basis data dilakukan menggunakan ERD (Entity Relationship Diagram). Tahapan ERD diawali dengan mengidentifikasi dan menetapkan seluruh himpunan entitas yang terlibat. Berikut pada tabel 1 entitas yang terlibat dalam sistem aplikasi pemesanan makan makanan berbasis mobile, disertai dengan jenis entitas dan keterangan.
TABEL I

DAFTAR ENTITAS YANG TERLIBAT

\begin{tabular}{|l|l|l|l|}
\hline No. & Nama Entitas & $\begin{array}{l}\text { Jenis } \\
\text { Entitas }\end{array}$ & Keterangan \\
\hline 1 & user & $\begin{array}{l}\text { Entitas } \\
\text { kuat }\end{array}$ & $\begin{array}{l}\text { Entitas yang berisi data user } \\
\text { baik admin, pelayan, kasir, } \\
\text { dapur, dan operator. }\end{array}$ \\
\hline 2 & menu & $\begin{array}{l}\text { Entitas } \\
\text { lemah }\end{array}$ & $\begin{array}{l}\text { Entitas yang berisi data menu } \\
\text { yang tersedia. }\end{array}$ \\
\hline 3 & kategori & $\begin{array}{l}\text { Entitas } \\
\text { kuat }\end{array}$ & $\begin{array}{l}\text { Entitas yang berisi data kategori } \\
\text { menu b berisi data }\end{array}$ \\
\hline 4 & pemesanan & $\begin{array}{l}\text { Entitas } \\
\text { lemah }\end{array}$ & $\begin{array}{l}\text { Entitas yang bemesanan yang } \\
\text { transaksi pan peris data } \\
\text { dimasukkan oleh pelayan }\end{array}$ \\
\hline 5 & pesanantar & $\begin{array}{l}\text { Entitas } \\
\text { lemah }\end{array}$ & $\begin{array}{l}\text { Entitas yang berisi } \\
\text { transaksi pesan antar yang } \\
\text { dimasukkan oleh operator }\end{array}$ \\
\hline 6 & belanja & $\begin{array}{l}\text { Entitas } \\
\text { lemah }\end{array}$ & $\begin{array}{l}\text { Entitas yang berisi data } \\
\text { transaksi belanja yang } \\
\text { dimasukkan oleh dapur }\end{array}$ \\
\hline 7 & $\begin{array}{l}\text { pemesanan_- } \\
\text { detil }\end{array}$ & $\begin{array}{l}\text { Entitas } \\
\text { lemah }\end{array}$ & $\begin{array}{l}\text { Entitas yang berisi data detail } \\
\text { setiap transaksi pemesanan }\end{array}$ \\
\hline 8 & pesanantar_detil & $\begin{array}{l}\text { Entitas } \\
\text { lemah }\end{array}$ & $\begin{array}{l}\text { Entitas yang berisi data detail } \\
\text { setiap transaksi pesan antar }\end{array}$ \\
\hline 9 & belanja_detil & $\begin{array}{l}\text { Entitas } \\
\text { lemah }\end{array}$ & $\begin{array}{l}\text { Entitas yang berisi data detail } \\
\text { setiap transaksi belanja }\end{array}$ \\
\hline 10 & $\begin{array}{l}\text { pemesanan_ } \\
\text { smtr }\end{array}$ & $\begin{array}{l}\text { Entitas } \\
\text { kuat }\end{array}$ & $\begin{array}{l}\text { Entitas yang menampung data } \\
\text { sementara detail pemesanan }\end{array}$ \\
\hline 11 & pesanantar_smtr & $\begin{array}{l}\text { Entitas } \\
\text { kuat }\end{array}$ & $\begin{array}{l}\text { Entitas yang menampung data } \\
\text { sementara detail transaksi pesan } \\
\text { antar }\end{array}$ \\
\hline 12 & belanja_smtr & $\begin{array}{l}\text { Entitas } \\
\text { kuat }\end{array}$ & $\begin{array}{l}\text { Entitas yang menampung data } \\
\text { sementara detail transaksi } \\
\text { belanja }\end{array}$ \\
\hline & & &
\end{tabular}

Setelah diketahui entitas apa saja yang terlibat pada sistem, selanjutnya adalah menentukan atribut apa saja terdapat pada masing-masing entitas tersebut. Relasi antar Entitas kemudian ditentukan setelah entitas dan atribut terlah terdefenisi. Berikut ini beberapa relasi antar entitas yang terdapat pada sistem.
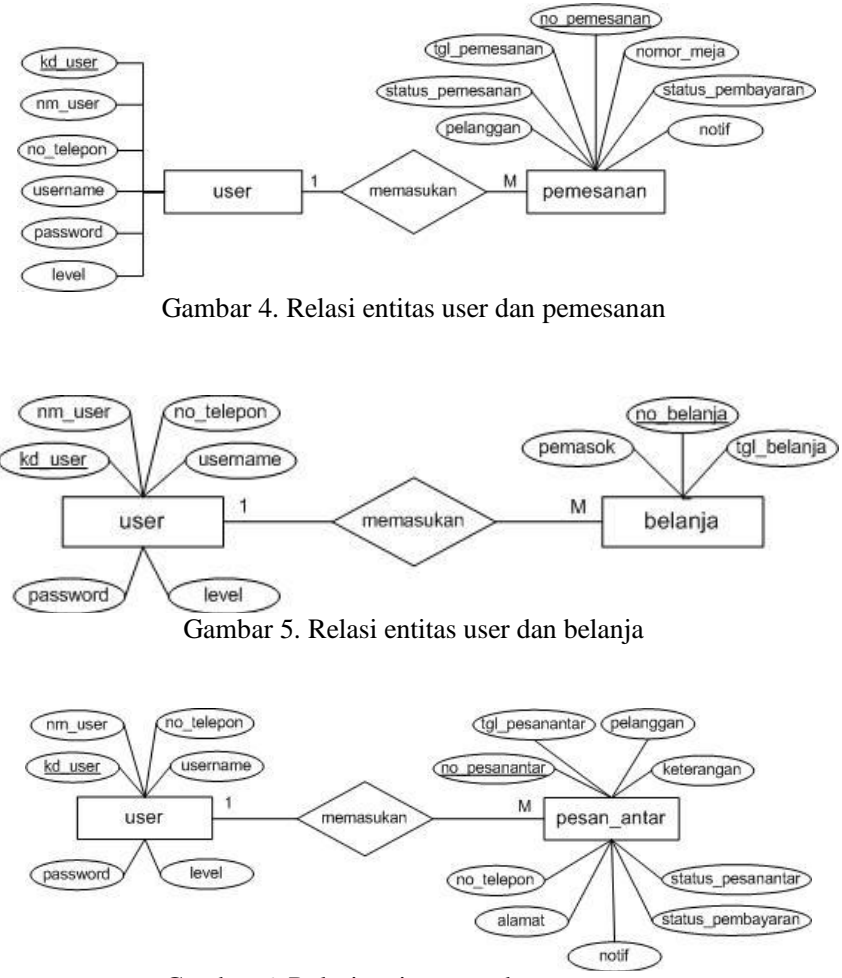

Gambar 6. Relasi entitas user dan pesanantar

Setelah relasi tersebut dibuat, kemudian ditransformasikan kedalam bentuk tabel. 


\section{PEMBAHASAN}

\section{A. Pengujian}

Pengujian aplikasi pemesanan makanan berbasis mobile ini dilakukan dengan menggunakan metode black-box. Proses pengujian dibagi menurut fungsi dari masing-masing menu sesuai dengan kegunaannya. Bentuk pengujian berupa cara pengguna menggunakan aplikasi.

Pengujian dilakukan pada dua jenis media perangkat keras, yakni pengujian aplikasi pada perangkat mobile yang digunakan oleh user pelayan dan pengujian aplikasi pada perangkat komputer desktop yang dignakan oleh user kasir, operator, dapur, dan admin.

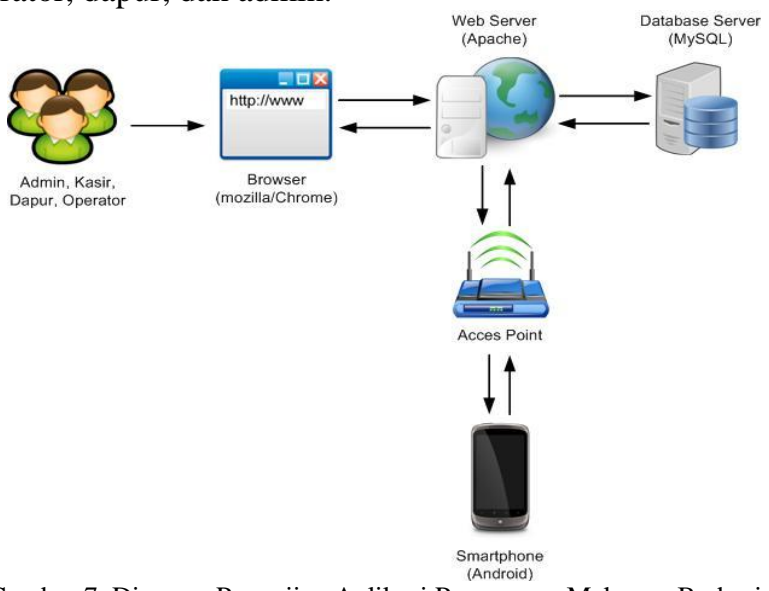

Gambar 7. Diagram Pengujian Aplikasi Pemesanan Makanan Berbasis

$$
\text { Mobile }
$$

Pengujian dimulai pada aplikasi yang berjalan pada perangkat mobile, aplikasi ini dijalankan oleh user pelayan. Bagian ini meliputi menu login, menu transaksi pemesanan, menu pilih item menu pemesanan, hapus item pemesanan, simpan pemesanan, menu daftar pemesanan, ubah item pesanan, menu logout. Berikut hasil pengujian menu halaman pelayan yang ditunjukkan pada Tabel II.

TABEL II

Hasil PenguJian MENu Halaman PELAyaAn

\begin{tabular}{|c|c|c|c|}
\hline $\begin{array}{c}\text { Nama } \\
\text { Pengujian }\end{array}$ & $\begin{array}{c}\text { Bentuk } \\
\text { Pengujian }\end{array}$ & $\begin{array}{c}\text { Hasil yang } \\
\text { Diharapkan }\end{array}$ & $\begin{array}{c}\text { Hasil } \\
\text { Penguji- } \\
\text { an }\end{array}$ \\
\hline Login & $\begin{array}{l}\text { Memasukkan } \\
\text { username dan } \\
\text { password }\end{array}$ & $\begin{array}{l}\text { Tampil halaman } \\
\text { utama pelayan }\end{array}$ & Berhasil \\
\hline $\begin{array}{l}\text { Pengujian } \\
\text { menu } \\
\text { transaksi } \\
\text { pemesanan }\end{array}$ & $\begin{array}{l}\text { Mengklik } \\
\text { tombol menu } \\
\text { transaksi } \\
\text { pemesannan }\end{array}$ & $\begin{array}{l}\text { Tampil form } \\
\text { untuk } \\
\text { memasukkan } \\
\text { informasi } \\
\text { pemesanan } \\
\end{array}$ & Berhasil \\
\hline $\begin{array}{l}\text { Pengujian } \\
\text { menu pilih } \\
\text { item menu } \\
\text { pemesanan }\end{array}$ & $\begin{array}{l}\text { Memilih item } \\
\text { menu dan } \\
\text { mengisi form } \\
\text { jumlah porsi } \\
\text { kemudian } \\
\text { mengklik } \\
\text { tombol pilih }\end{array}$ & $\begin{array}{l}\text { Tampil detil menu } \\
\text { yang dipilih pada } \\
\text { tabel daftar item }\end{array}$ & Berhasil \\
\hline $\begin{array}{l}\text { Pengujian } \\
\text { menu hapus } \\
\text { item menu } \\
\text { pemesanan }\end{array}$ & \begin{tabular}{lr}
\multicolumn{2}{l}{ Mengklik } \\
tombol hapus \\
pada baris \\
item & menu \\
yang & akan \\
dihapus & \\
\end{tabular} & $\begin{array}{ll}\text { Data item menu } & \text { mang } \\
\text { yang } & \text { dipilih } \\
\text { terhapus } & \end{array}$ & Berhasil \\
\hline $\begin{array}{l}\text { Pengujian } \\
\text { menu } \\
\text { simpan } \\
\text { pemesanan }\end{array}$ & $\begin{array}{l}\text { Mengklik } \\
\text { tombol } \\
\text { simpan }\end{array}$ & $\begin{array}{l}\text { Data transaksi } \\
\text { pemesanan } \\
\text { tersimpan dan } \\
\text { tampilan kembali } \\
\text { ke halaman utama }\end{array}$ & Berhasil \\
\hline
\end{tabular}

\begin{tabular}{|l|l|l|c|}
\hline $\begin{array}{l}\text { Pengujian } \\
\text { menu daftar } \\
\text { pemesanan }\end{array}$ & $\begin{array}{l}\text { Mengklik } \\
\text { tombol daftar } \\
\text { pemesanan }\end{array}$ & $\begin{array}{l}\text { Tampil daftar } \\
\text { pemesanan yang } \\
\text { memilki status } \\
\text { pemnayaran } \\
\text { 'belum' }\end{array}$ & Berhasil \\
\hline $\begin{array}{l}\text { Pengujian } \\
\text { menu ubah } \\
\text { item } \\
\text { pesanan } \\
\text { pada } \\
\text { pemesanan }\end{array}$ & $\begin{array}{l}\text { Mengklik } \\
\text { tombol ubah } \\
\text { menu }\end{array}$ & $\begin{array}{l}\text { Tampil form dan } \\
\text { data sebelumnya } \\
\text { untuk mengubah } \\
\text { informasi } \\
\text { pemesanan }\end{array}$ & Berhasil \\
\hline $\begin{array}{l}\text { Pengujian } \\
\text { menu } \\
\text { simpan } \\
\text { perubahan } \\
\text { pemesanan }\end{array}$ & $\begin{array}{l}\text { Mengklik } \\
\text { tombol } \\
\text { simpan }\end{array}$ & $\begin{array}{l}\text { item menu yang } \\
\text { dipesan berubah }\end{array}$ & Berhasil \\
\hline $\begin{array}{l}\text { Pengujian } \\
\text { menu } \\
\text { lougout }\end{array}$ & $\begin{array}{l}\text { Mengklik } \\
\text { tombol logout }\end{array}$ & $\begin{array}{l}\text { User } \\
\text { keluar dari sistem }\end{array}$ & Berhasil \\
\hline
\end{tabular}

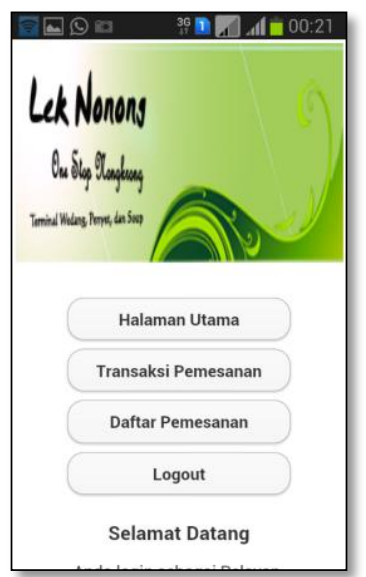

Gambar 8. Hasil pengujian login menampilkan halaman utama pelayan

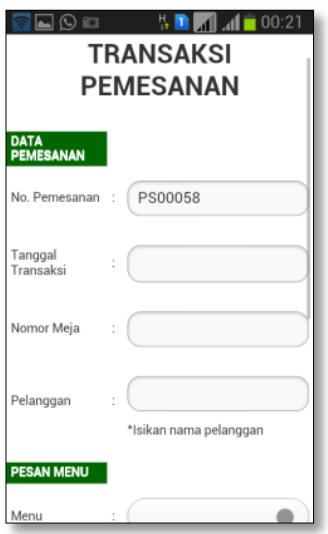

Gambar 9. Hasil Pengujian Menu Transaksi Pemesanan

Pengujian selanjutnya pada aplikasi yang berjalan pada perangkat komputer desktop, aplikasi ini dijalankan oleh user kasir, dapur, operator, dan admin. Bagian ini meliputi menu halaman kasir, menu halaman dapur, menu halaman operator, dan menu halaman admin. Berikut hasil pengujian menu halaman kasir yang ditunjukkan pada Tabel III.

TABEL III

Hasil PENGUJian MENU Halaman KasiR

\begin{tabular}{|l|l|l|c|}
\hline $\begin{array}{c}\text { Nama } \\
\text { Pengujian }\end{array}$ & $\begin{array}{c}\text { Bentuk } \\
\text { Pengujian }\end{array}$ & $\begin{array}{c}\text { Hasil yang } \\
\text { Diharapkan }\end{array}$ & $\begin{array}{c}\text { Hasil } \\
\text { Penguji- } \\
\text { an }\end{array}$ \\
\hline Login & $\begin{array}{l}\text { Memasukka } \\
\mathrm{n} \text { username, } \\
\text { password, } \\
\text { dan level }\end{array}$ & $\begin{array}{l}\text { Tampil halaman } \\
\text { utama kasir }\end{array}$ & Berhasil \\
\hline
\end{tabular}




\begin{tabular}{|c|c|c|c|}
\hline $\begin{array}{l}\text { Pengujian } \\
\text { menu daftar } \\
\text { pemesanan }\end{array}$ & $\begin{array}{l}\text { Mengklik } \\
\text { tombol menu } \\
\text { daftar } \\
\text { pemesanan }\end{array}$ & $\begin{array}{lr}\text { Tampil daftar } \\
\text { pemesanan yang } \\
\text { memiliki status } \\
\text { pemesanan 'sudah } \\
\text { jadi' dan status } \\
\text { pembayaran } \\
\text { 'belum' }\end{array}$ & Berhasil \\
\hline $\begin{array}{l}\text { Pengujian } \\
\text { menu detil } \\
\text { pemesanan }\end{array}$ & $\begin{array}{l}\text { Mengklik } \\
\text { tombol detil } \\
\text { pemesanan } \\
\text { pada salah } \\
\text { satu daftar } \\
\text { pemesanan }\end{array}$ & $\begin{array}{l}\text { Tampil daftar } \\
\text { detil pemesanan }\end{array}$ & Berhasil \\
\hline $\begin{array}{l}\text { Pengujian } \\
\text { tombol } \\
\text { hitung } \\
\text { transaksi } \\
\text { pembayaran }\end{array}$ & $\begin{array}{l}\text { Memasukkan } \\
\text { informasi } \\
\text { uang bayar } \\
\text { dan mengklik } \\
\text { tombol hitung }\end{array}$ & $\begin{array}{l}\text { Tampil informasi } \\
\text { uang kembali }\end{array}$ & Berhasil \\
\hline $\begin{array}{l}\text { Pengujian } \\
\text { menu cetak } \\
\text { nota } \\
\text { pembayaran } \\
\text { pemesanan }\end{array}$ & $\begin{array}{l}\text { Mengklik } \\
\text { tombol cetak } \\
\text { pembaya-ran }\end{array}$ & $\begin{array}{lr}\text { Nota langsung } \\
\text { dicetak } \\
\text { menggunakan } \\
\text { printer } \\
\text { kembali dan } \\
\text { tampilan daftar } \\
\text { pemesanan } & \\
\end{array}$ & Berhasil \\
\hline $\begin{array}{l}\text { Pengujian } \\
\text { menu daftar } \\
\text { pesan antar }\end{array}$ & \begin{tabular}{l}
\multicolumn{2}{l}{ Mengklik } \\
tombol menu \\
daftar pesan \\
antar
\end{tabular} & $\begin{array}{l}\text { Tampil daftar } \\
\text { pesan antar yang } \\
\text { memiliki status } \\
\text { pembayaran } \\
\text { 'belum' }\end{array}$ & Berhasil \\
\hline $\begin{array}{l}\text { Pengujian } \\
\text { menu detil } \\
\text { pesan antar }\end{array}$ & $\begin{array}{l}\text { Mengklik } \\
\text { tombol detil } \\
\text { pesan } \\
\text { antarpada } \\
\text { salah satu } \\
\text { daftar pesan } \\
\text { antar }\end{array}$ & $\begin{array}{l}\text { Tampil daftar } \\
\text { detil pesan antar }\end{array}$ & Berhasil \\
\hline $\begin{array}{l}\text { Pengujian } \\
\text { tombol } \\
\text { hitung pada } \\
\text { nota pesana } \\
\text { antar }\end{array}$ & $\begin{array}{l}\text { Memasukkan } \\
\text { informasi } \\
\text { uang bayar } \\
\text { dan mengklik } \\
\text { tombol hitung }\end{array}$ & $\begin{array}{l}\text { Tampil informasi } \\
\text { uang kembali }\end{array}$ & Berhasil \\
\hline $\begin{array}{l}\text { Pengujian } \\
\text { menu cetak } \\
\text { nota } \\
\text { pembayaran } \\
\text { pesan antar }\end{array}$ & $\begin{array}{l}\text { Mengklik } \\
\text { tombol cetak } \\
\text { pembayaran }\end{array}$ & $\begin{array}{lr}\text { Nota langsung } \\
\text { dicetak } \\
\text { menggunakan } \\
\text { printer } \\
\text { kembali dan } \\
\text { tampilan daftar } \\
\text { pesan antar } & \\
\end{array}$ & Berhasil \\
\hline $\begin{array}{l}\text { Pengujian } \\
\text { menu } \\
\text { lougout }\end{array}$ & $\begin{array}{l}\text { Mengklik } \\
\text { tombol logout }\end{array}$ & $\begin{array}{l}\text { User kasir keluar } \\
\text { dari sistem }\end{array}$ & Berhasil \\
\hline
\end{tabular}

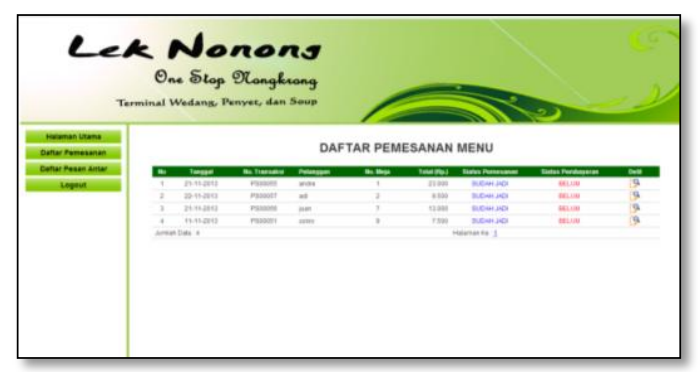

Gambar 10. Hasil pengujian menampilkan daftar pemesanan (kasir)

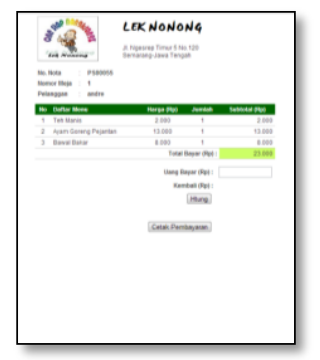

Gambar 11. Hasil pengujian menampilkan daftar detil pemesanan

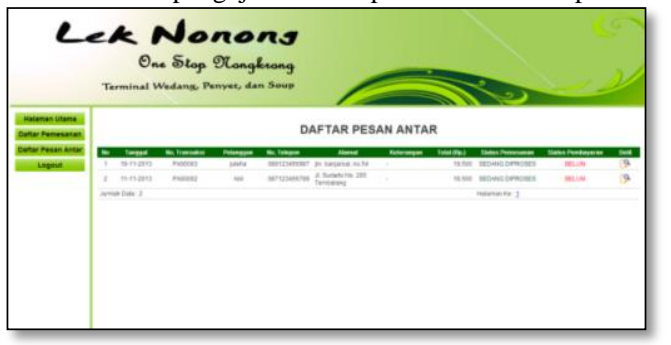

Gambar 12. Hasil pengujian menampilkan daftar pesan antar (kasir)

\section{KESIMPULAN DAN SARAN}

Pada bagian ini akan dijelaskan kesimpulan dan saran dari hasil perancangan dan pembahasan.

\section{A. Kesimpulan}

Berdasarkan hasil pengujian dan analisis aplikasi pemesanan makanan berbasis mobile, maka dapat disimpulkan beberapa hal sebagai berikut :

1) Aplikasi yang berjalan pada perangkat mobile hanya dapat diakses oleh pengguna pelayan.

2) Aplikasi yang berjalan pada perangkat komputer desktop dapat diakses oleh pengguna kasir, operator, dapur, dan admin.

3) Laporan transaksi yang ditampilkan berupa total transaksi dan total pemasukan dari transaksi, tidak berupa neraca laba-rugi.

4) Berdasarkan hasil pengujian aplikasi pemesanan makanan berbasis mobile yang telah dilakukan, seluruh fungsi menu yang ada dalam aplikasi tersebut telah berhasil sesuai dengan fungsinya.

\section{B. Saran}

Terdapat beberapa saran dari hasil penelitian yaitu sebagai berikut :

1) Melakukan pengembangan lebih lanjut agar aplikasi dapat menampilkan laporan transaksi menggunakan neraca laba-rugi.

2) Melakukan pengembangan lebih lanjut agar aplikasi dapat menangani permintaan pelanggan yang tidak tersedia pada pilihan menu, untuk meningkatkan kepuasan pelanggan.

3) Melakukan pengembangan lebih lanjut agar aplikasi dapat menampilkan denah meja, untuk memudahkan pengguna kasir dalam menampilkan tagihan pembayaran.

\section{DAFTAR PUSTAKA}

[1] A.S, Rosa dan M. Shalahuddin, Modul Pembelajaran Rekayasa Perangkat Lunak, Bandung : Modula, 2011.

[2] Ariefianto, Himawan, Jurnal Ilmiah: Perancangan Dan Implementasi Aplikasi Pemesanan Makanan Dan Minuman Berbasis Client Server Dengan Platform Android (Studi Kasus Waroeng Steak And Shake), 2012.

[3] Hirin, A.M dan Virgi, Cepat Mahir Pemrograman Web dengan PHP dan MySQL, Jakarta : Prestasi Pustakarya, 2011.

[4] Kadir, Abdul, Mudah Mempelajari Database MySQL, Yogyakarta : Andi, 2010.

[5] Kristanto, Andri, Rekayasa Perangkat Lunak (Konsep Dasar), Yogyakarta : Gava Media, 2004. 
[6] Oktavian, Diar Puji, Menjadi Programmer Jempolan Menggunakan PHP, Yogyakarta : Mediakom, 2010.

[7] Sidik, Betha, Javascript, Bandung : Informatika, 2011.

[8] Taufiq, Andik, Pemrograman Grafik dengan Java, Bandung : Informatika, 2010.

[9] Thohari, Afandi Nur Aziz, Jurnal Ilmiah : Pembuatan Aplikasi Mobile Learning Sebagai Sarana Pembelajaran Di Lingkungan Universitas Diponegoro, Semarang, 2013.

[10] Windarto, Yudi Eko, Jurnal Ilmiah : Sistem Informasi Geografis Manajemen Aset di PT. PLN (Persero) Area Pelayanan Jaringan Surakarta, 2012.

[11] ---, Membuat Sendiri Aplikasi Web Mobile Menggunakan JQuery Mobile, Yogyakarta : Kerjasama Penerbit Andi dan Wahana Komputer, 2013.

[12] ---, ShortCourse: PHP Programming, Yogyakartya : Kerjasama Penerbit Andi dan Wahana Komputer, 2009.

\section{BIODATA PENULIS}

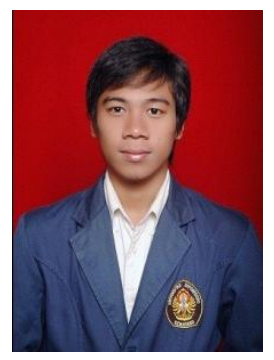

Adi Putra Nugraha lahir di Sumbawa Besar, 25 Maret 1991. Telah menempuh pendidikan dasar di SDN Lempeh Sumbawa, melanjutkan ke SMPN 1 Sumbawa, dan meneruskan pendidikan tingkat atas di SMAN 1 Sumbawa, lulus tahun 2009. Dari tahun 2009 sampai dengan saat ini tengah menempu pendidikan strata satu di Program Studi Sistem Komputer, Universitas Diponegoro, Semarang, Indonesia. 